\section{HSE}

Historia Social y de la Educación

Social and Education History

\section{Hipatia Press}

www.hipatiapress.com

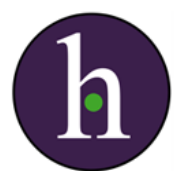

Instructions for authors, subscriptions and further details:

http://hse.hipatiapress.com

\title{
Ens Farem Humans?
}

Lluís Batista ${ }^{1}$

1) Institut Català de Paleoecología Humana i Evolució Social (IPHES), España

Date of publication: June $23^{\text {rd }}, 2015$

Edition period: Edition period: June 2015-October 2015

To cite this article: Batista, LL. (2015). Ens farem humans? [Review of the book]. Social and Education History, 4(2), 211-213.

doi: $10.17583 /$ hse.2015.1580

To link this article: http://doi.org/10.17583/hse.2015.1580

\section{PLEASE SCROLL DOWN FOR ARTICLE}

The terms and conditions of use are related to the Open Journal System and to Creative Commons Attribution License (CC-BY). 
HSE - Social and Education History Vol. 4 No. 1 Febraury 2015 pp. 211-213

\section{Reviews (I)}

Carbonell, Eudald. (2014). Ens farem humans?. Valls (Tarragona): Cossetània. ISBN: 978-84-9034-306-7.

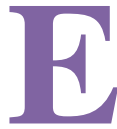

n este nuevo libro, Eudald Carbonell nos ofrece una serie de reflexiones en torno al futuro de nuestra especie. Tomando como base que el Homo sapiens ya puede decidir su pròpia evolución biológica gracias a la ciencia y la tecnología, el autor se plantea el concepto de "Humanización" de la humanidad como algo que estamos en vías de alcanzar. La obra resultará interesante no solo a los amantes de la paleoantropologia, sino a cualquiera que desee reflexionar sobre el futuro evolutivo del ser humano.

Colaborando con el biólogo Policarp Hortolà, el autor hace un repaso a todas y cada una de las características sobre las que es preciso reflexionar para darnos cuenta de que nuestra especie aún no ha alcanzado la humanización.

La socialización del conocimiento adquirido por nuestra especie es el factor clave que nos ha permitido alcanzar el estatus que tenemos actualmente. Este factor fue vital durante todo el proceso de hominización, ya que permitió a los humanos ocupar un lugar predominante entre los seres vivos del planeta.

Aún realizamos esta socialización del conocimiento, y posiblemente en mayor medida que en el pasado, ya sea reciente o remoto, pero el proceso debe avanzar mucho más. La conciencia crítica que hemos de tener como 


\section{Batista - Ens Farem Humans?[Book Review]}

especie única en el planeta, sin perjuicios sobre distinciones étnicas, religiosas, sociales y de otras índoles, solo se alcanzará cuando todos los integrantes de nuestra especie puedan beneficiarse del conocimiento procedente de la ciencia.

La especie humana se ha de resocializar, y Eudald establece 21 conceptos, aspectos o retos que nuestra especie ha de desarrollar para completar la humanización, que tiene como base la socialización de la tecnología. Los humanos nos adaptamos a través de la tecnología y el lenguaje. Si socializamos la tecnología y somos capaces de compartirla y ponerla al alcance de todos, podremos acelerar el proceso de humanización, de otro modo, podríamos tener una crisis de especie.

Para ir alcanzando este objetivo, se ha de prestar atención a aspectos que pueden constituir retos, como la integración de la diversidad, la conciencia operativa, la competencia humana, el aprendizaje intergeneracional, el conocimiento crítico y la progresiva conversión de nuestra especie en humanos tecnosociales.

La ciencia como mecanismo vertebrador del desarrollo humano es una consecuencia de la evolución social y cultural del orden de los primates. Hace falta una socialización de la ciencia como mecanismo básico de adaptación que permita en un futuro la integración de la diversidad humana. La pérdida de diversidad afecta negativamente a la memoria del sistema, ya que el intercambio desigual produce una falta de competencia en gran número de humanos.

La sustitución de las leyes que gobiernan el orden natural por la organización humana es el gran reto de nuestra especie en el siglo XXI. Por primera vez en la historia del ser humano, somos conscientes de este desafío. El paso de la inteligencia operativa a la conciencia operativa es un gran salto que hemos de realizar. Solo en este concepto de transformación podemos ser capaces de caminar seguros hacia una conciencia crítica de especie. Esta debe basarse en la integración de la diversidad, es decir, de la capacidad humana para capturar toda la memoria del sistema tanto a nivel individual como colectivo, tanto a nivel de cultura como de especie. Hemos de ser capaces de cambiar valores por conciencia, una conciencia crítica de especie.

La humanos hemos de converger, y no competir entre nosotros, tendríamos que intentar cambiar nuestra competitividad por competencia. 
Es curioso que nos podamos destruir como especie, pero no redimirnos. Una especie competente no ha de competir. No hemos de competir, hemos de utilizar nuestra competencia, y no competir. La competencia nos hace desarrollarnos como especie, pero la competitividad nos puede destruir.

Estamos acelerando la historia a través de la tecnología, pero podría haber un colapso. Antes, todo el mundo sabía hacer instrumentos de piedra, bien o mal, hoy en día, los usuarios no entendemos el principio del 95\% de los elementos tecnológicos que utilizamos.

Antes, la experiencia venía de personas que habían vivido 60 años, por poner un ejemplo, y ahora es la persona joven la que debe hacer funcionar la tecnología y enseñarla, en muchas ocasiones, a los adultos. Actualmente la experiencia de los mayores se utiliza para acompañar, no para dirigir.

Eudald Carbonell, en su obra, opina que, trabajando estos aspectos lograremos que en el camino de nuestra evolución, la lógica sustituya al azar y la selección natural quede sustituida por una selección cultural. Entonces habremos conseguido la completa humanización.

Lluís Batista Institut Català de Paleoecología Humana i Evolució Social (IPHES) 